\title{
Design and working of Suspension System to Generate Electric Power
}

\author{
Somashekar R, Santhosh H C, Sahana J, Sarvesh Akshay C
}

\begin{abstract}
The objective of the work is to design and working of a of suspension system to generate electric power.To achieve this drive mechanism such as rack and pinion and gear mechanisms are used. Based on the requirements, the model is designed which can produce electric power with just footstep or less manual power. The analysis was carried out for the for the model, which shows that power generation is well within the limit.
\end{abstract}

Key Words-Rack, pinion, D C generator, battery, inverter control

\section{INTRODUCTION}

It was known to form electricity by motion of parts in a rotating wheel. After analysis of a different parts, using relativemoment available in a suspension system of a automobile.In this new developing age of the electric automobiles, everything has to be updated. In this new development the electric vehicle will be launched like the way bullock cars were in earlier ages, this may take several years, for now this is the stepping stone. We have batteries and electrical and electronic parts that weighsheavy together with increased masses of wiring. We have a heavy noisy, oily, vibratingIC enginesin the past.Introducing smart electronic surfaces, wireless links, laminar conformal batteries and mini turbine range extenders. We have really jumped from old engine to new advanced turbo charged engine with safety, comfort and space for passenger and drivers. If comfort should be there shock absorbers plays an important role, and to generate electricity with it.

\section{METHODOLOGY}

\section{A. Component Details}

A linear actuator that has a pair of gears which changes linear motion into rotating motion is nothing but rack and pinion. A gear called "the pinion" connects the teeth on a straight "gear" bar named "the rack"; as shown in fig.1. linear motion of the barcreates rotation motion to the gear,this process leads to generation of electricity.

Manuscript received on January 27, 2021

Revised Manuscript received on February 22, 2021

Manuscript published on February 28, 2021

Somashekar R, Assistant Professor Department of Mechanical Engineering, Don Bosco Institute of Technology Email: somashekarr@hotmail.com

Sahana J, Student of Don Bosco Institute of Technology, Department. of Mechanical Engineering Don Bosco Institute of Technology Bangalore India. Email: jagadeeshsahana1@gmail.com

Akshay C, Student of Don Bosco Institute of Technology, Department of Mechanical Engineering Don Bosco Institute of Technology Bangalore, India. Email: akshaymath130@ gmail.com

Santhosh H C, Student of Don Bosco Institute of Technology, Department. of Mechanical Engineering Don Bosco Institute of Technology Bangalore, India. Email: santhu26982@gmail.com

Sarvesh, Student of Don Bosco Institute of Technology, Department. of Mechanical Engineering Don Bosco Institute of Technology Bangalore, India. Email: Sarveshm8788@gmail.com

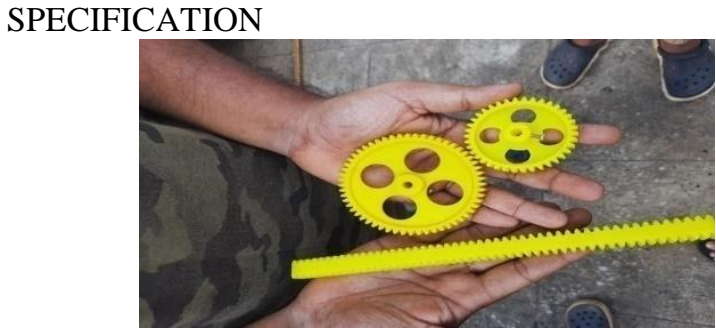

Figure.1Rack and pinion

Material -

\section{Plastic}

Function- : : To change the translator motion in to rotary motion

Properties : Highly durable, electrically and thermally insulative, resistance to shock, corrosion, chemicals and water.

\section{B. Doubly Fed Induction Motor}

The doubly fed induction motor is a required motor for industry and a widely usedgenerator production. With the help of rheostats its speed and torque can be managed or with the help of frequency converter engaged to the rotor winding. To take advantages of them it is mandatory to provide electrical connection between the rotor winding and the rheostat or the frequency converter. It is easy to use brushes and slip rings to access the rotor winding.

\section{SPECIFICATION}

\section{$>12 \mathrm{~V}-200 \mathrm{RPM}$}

$>$ Current $-7 \mathrm{Ah}$

$>3.6 \mathrm{KG} \cdot \mathrm{CM}$ torque DC gear head motor

$>$ Good one for between speed and torque for small robotic designs.
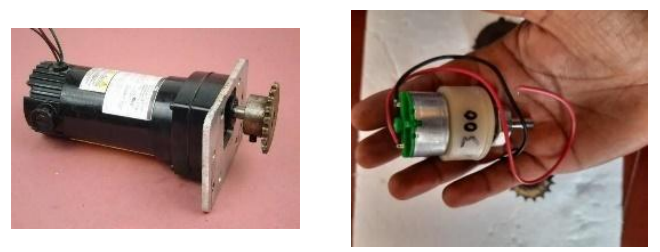

Fig 2. Doubly fed induction motor

TABLE I. SPECIFICATIONS OF DC MOTOR

\begin{tabular}{|c|c|c|}
\hline Characteristic & Value & Unit \\
\hline Operating Voltage & $4.5-1.8$ & $\mathrm{~V}$ \\
\hline $\begin{array}{l}\text { Startup Torque } \\
\text { (kilogram-force centimeter) }\end{array}$ & 3.60 & Kg.cm \\
\hline Startup Torque (inch-pound) & 3.10 & Inch.lbf \\
\hline Gear Ratio & $30: 1$ & \\
\hline No-Load Current (12V) & 0.053 & $\mathrm{~A}$ \\
\hline Stall Current & 1.50 & A \\
\hline No Load Speed (12V) & 200 & RPM \\
\hline
\end{tabular}




\section{Design and working of Suspension System to Generate Electric Power}

\section{BEARINGS}

A bearing is a machine element, which supports another machine element as shown in fig 3. It provides a movement relative to the mating surfaces, while transmitting the load. In this model gearbox roller bearings are taken, the ball or roller bearing consists of an inner part, which is placed on the shaft or journal, and the outer part, which is supported by the housing. In between the inner and outer parts there are round objects or rollers, number of round objects or rollers is used and these are placed at proper distance by retainers so that they do not come in contact with each other.

\section{SPECIFICATIONS}

$>$ Material - High CARBON CHROMIUM STEEL.

$>$ Function - Support a moving element and to guide or direct its motion, while stopping motion in the direction of given load.

$>$ Properties-High Compressive Strength, High Fatigue Strength, High Thermal Conductivity,Low Thermal Expansion, Low Co-efficient of friction.

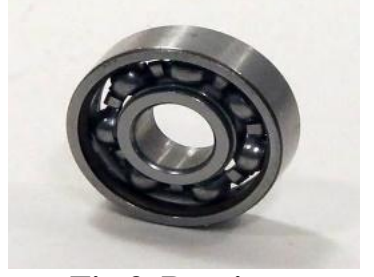

Fig 3. Bearings

\section{CHAIN SPROCKET}

It is a profiled wheel with teeth, or cogs, around it, that mesh with a chain, track or other perforated or indented material. Generally any wheel can be called as sprocket upon which radial protrusion connects a chain passing over it, typically sprockets do not have a flange.

\section{SPECIFICATION}

\section{$>$ Material - Cast IRON}

$>$ Function -To transmit rotary motion between two shafts where gears are not usable or to give linear motion to a track, tape etc...

$>$ Properties - Hardness, Toughness, Ductility, Elasticity.

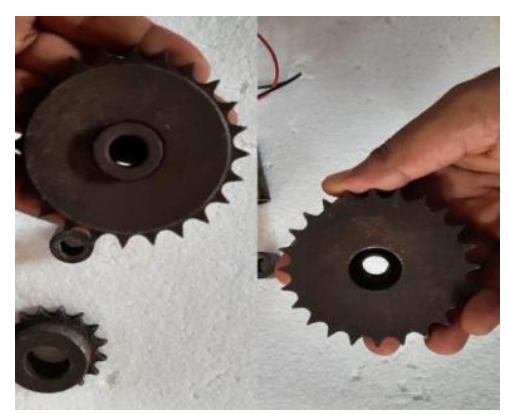

\section{MODELDESIGN}

The component is studied in detail for its size, shape and variation in cross-section. In this section step by step approach to the design of press tools based on experience,
Fig 4. Chain sprocket

empiricism and expertise as applied to "Clamping Plate" and various design calculations are given below:

\section{A. Cut out plate

$\begin{array}{ll}\text { Length } & : 160 \mathrm{~mm} \\ \text { Width } & : 100 \mathrm{~mm} \\ \text { Thickness } & : 20 \mathrm{~mm}\end{array}$

B. Side plate

Length : $150 \mathrm{~mm}$

C. Rack

$\begin{array}{lll}\text { length } & : & 178-180 \mathrm{~mm} \\ \text { No. of teeth } & : & 18\end{array}$

D. Pinion

Bore dia : $52 \mathrm{~mm}$

Outer dia $\quad: \quad 100$

E. Bolts

$\begin{array}{lll}\text { Dia } & : & 10 \mathrm{~mm} \\ \text { Length } & : & 300 \mathrm{~mm}\end{array}$

F. Bearings

Type : Pillow block

Inner dia : $15 \mathrm{~mm}$

Outer dia : $30 \mathrm{~mm}$

G. Battery

$\begin{array}{lll}\text { Voltage capacity } & : & 12 \mathrm{v} \text { Current }-7 \mathrm{Ah} \\ \text { Speed capacity } & : & 200 \mathrm{rpm}\end{array}$

I. Design

i. Specification of pinion:

- $\quad$ Material $=\mathrm{CI}$

- Outside Diameter $=25.00 \mathrm{~mm}$

- Circular Pitch $=\pi / \mathrm{d}=0.1256 \mathrm{~mm}$

- $\quad$ Pressure Angle $(\alpha)=21^{0}$

- Pitch Diameter $(\mathrm{P})=\mathrm{N} / \mathrm{P}=0.8 \mathrm{~mm}$

- Addendum $=1 / 25=0.04 \mathrm{~mm}$

- Dedendum $=1.157 / 25=0.04628 \mathrm{~mm}$

ii. Specification of rack:

- Material $=\mathrm{CI}$

- Width $=1.50 \mathrm{~mm}$

- Height $=130.00 \mathrm{~mm}$

- $\quad$ Pitch Circle Diameter $=25 \mathrm{~mm}$ x $3.14=78.50$ $\mathrm{mm}$

iii. Calculation of Gears:

Assuming $d 1=50 \mathrm{~mm} ; d 2=100 \mathrm{~mm} ; \alpha=20^{\circ} ; \mathrm{m}=$ 2mm;

$N 2=100 \mathrm{rpm}$

Transmission Ratio $=i=\frac{N_{1}}{N_{1}}=\frac{Z_{2}}{Z_{2}}=\frac{d_{2}}{d_{2}}$

$$
\begin{aligned}
& i=d_{2} / d_{1}=100 / 50=2 \\
\therefore \mathrm{i}=2, N 1 / N 2=\mathrm{i}=\mathrm{N} 1 / 100=2 & \\
& \mathrm{~N} 1=100 \times 2
\end{aligned}
$$

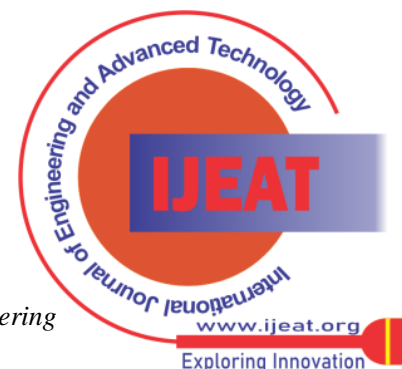


$\mathrm{N} 1=200 \mathrm{rpm}$

iv. Number of Teeth:

$$
\begin{aligned}
& Z_{1}=\frac{d_{1}}{m}=\frac{50}{2}=25 \text { teeth } \\
& Z_{2}=\frac{d_{2}}{m}=\frac{100}{2}=\text { teeth }
\end{aligned}
$$

v. Width of the Face:

$$
\mathrm{B}=10 \times \mathrm{m}=10 \times 2=20 \mathrm{~mm}
$$

vi. Full depth involute:

- Addendum $(h a)=1 \times \mathrm{mm}=1 \times 2=2 \mathrm{~mm}$

- Dedendum $(h i)=1.25 \times \mathrm{m}=1.25 \times 2=2.5 \mathrm{~mm}$

- Whole Depth $(h)=2.25 \times \mathrm{m}=2.25 \times 2=4.5 \mathrm{~mm}$

- Clearance $(c)=0.25 \times \mathrm{m}=0.25 \times 2=0.5 \mathrm{~mm}$

Outer diameter of pinion $\left(d_{a 1}\right)=\left(Z_{1}+2\right) \mathrm{m}$

$$
=(25+2) 2
$$

$=54 \mathrm{~mm}$

- Outside diameter of gear $\left.d_{a 2}\right)=\left(Z_{2}+2\right) \mathrm{m}$

$$
\begin{aligned}
& =(50+2) 2 \\
& =104 \mathrm{~mm}
\end{aligned}
$$

- Tooth thickness (s) $=\frac{\pi}{2} \times m=\frac{\pi}{2} \times 2=3.14 \mathrm{~mm}$

- Working Depth $\left(h^{\prime}\right)=2 \times m=2 \times 2=4 \mathrm{~mm}$

- Circular Pitch (p) $=\pi x m=\pi x 2=6.28 \mathrm{~mm}$

- Base circle $d_{1}$ of pinion $=\left(d_{b 1}\right)=d_{1} \cos \alpha$

$$
\begin{aligned}
& =50 \cos 20 \\
& =46.9 \mathrm{~mm}
\end{aligned}
$$

- Base circle $d_{2}$ of pinion $=\left(d_{b 2}\right)=d_{1} \cos \alpha$

$$
\begin{aligned}
& =100 \cos 20 \\
& =93.97 \mathrm{~mm}
\end{aligned}
$$

vii. Gear load calculation:

- $\mathrm{d}=50 \mathrm{~mm} ; N_{1}=200 \mathrm{rpm} ; Z_{1}=25$ teeth

- $\mathrm{y}=0.154-(0.192 / 25)=0.11752 \mathrm{~mm}$

- Design based on power:

$$
\begin{gathered}
\frac{F_{t}=9550 N C_{s}}{n r} \\
\begin{array}{c}
F_{t}=9550 \times\left(1.358 \times 10^{3}\right) \times 1.5 \\
200 \times 25
\end{array} \\
F_{t}=3890.67 \mathrm{~N}
\end{gathered}
$$

- Design based on Levi's Equation:

$$
\begin{aligned}
& F_{t}=\sigma_{\circ} b y P K_{v} \\
& \sigma \circ=140 \mathrm{MPa}=140 \mathrm{~N} / \mathrm{mm}^{2} \\
& \mathrm{~b}=10 \mathrm{~m}=10 \times 2=20 \mathrm{~mm} \\
& \mathrm{y}=0.11752 \\
& \mathrm{P}=\pi m=\pi \times 2=6.283 \mathrm{~mm}
\end{aligned}
$$

$K v=$ velocity factor

$$
\begin{aligned}
& V_{m}=\frac{\pi d n}{60000}=\frac{\pi \times 50 \times 200}{60000} \\
& V_{m}=0.523 \mathrm{~m} / \mathrm{s}
\end{aligned}
$$

Since $V m \leq 7.5 \mathrm{~m} / \mathrm{s}$

$$
\begin{aligned}
K_{v} & =\frac{3}{3+V_{m}}=\frac{3}{3+0.523} \\
K_{v} & =0.8515 \\
\therefore F t & =\sigma^{\circ} b y P K v
\end{aligned}
$$

$F t=140 \times(20) \times 0.11752 \times 6.823 \times 0.8591$

$F t=1759.40 \mathrm{~N}$

- Check for Stress:

Allowable Stress $(\sigma a l l)=\left(\sigma^{\circ} K v\right)$ all

$$
\begin{aligned}
& =140 \times 0.919 \\
& =128.66 \mathrm{~N} / \mathrm{mm}^{2}
\end{aligned}
$$

Induced Stress $\left(\sigma_{\text {ind }}\right)=\left(\sigma_{0} K_{v}\right)_{\text {ind }}-\frac{F_{t}}{b y p}$

$$
\begin{aligned}
= & \frac{1759.40}{20 \times 0.11752 \times 6.283} \\
& \therefore \sigma_{\text {all }} \geq \sigma_{\text {ind }}
\end{aligned}
$$

Hence design is safe

-Check for Dynamic Load

$$
\begin{aligned}
& F_{d}=F_{t}+\frac{21 V_{m}\left(F_{t}+b_{c}\right)}{21 V_{m}+\sqrt{F_{t}}+\sqrt{B_{c}}} \\
& \mathrm{f}=0.025 \text { with } \mathrm{m}=2 \mathrm{~mm}
\end{aligned}
$$

For Steel and Steel combination $\mathrm{c}=290 \mathrm{KN} / \mathrm{m}=290 \mathrm{~N} / \mathrm{mm}$

$$
\begin{aligned}
& \frac{1}{C_{2}} X K \\
& =0.111 f \text { for } 20^{0} \mathrm{FD}
\end{aligned}
$$

$\mathrm{k}=0.111 \mathrm{x} 0.025$

$\mathrm{k}=2.775 \times 10^{3}$

$$
\begin{gathered}
F_{d}=1899.99+\frac{21 \times 0.261(1899.99+20 \times 290))}{21 \times 0.261+\sqrt{1899.99+20 \times 290)}} \\
F_{d} \\
F_{w} \\
\mathrm{O}=\frac{2 Z_{2}}{Z_{2}+Z_{2}}=\frac{2 \times 50}{25+50}=1.33
\end{gathered}
$$

For safe design






\section{Design and working of Suspension System to Generate Electric Power}

$F w \geq F d$

50(20) (1.33) $\mathrm{k} \geq 452.68$

$\mathrm{k} \geq 0.340$

$\mathrm{k}=\frac{1.43 \sigma 2 \sin \alpha}{E_{0}}$

$\mathrm{E}_{0}=\frac{2 E_{1} E_{2}}{E_{1}+E_{2}}$

$\mathrm{k}=\left(1.43 \sigma^{2} 20\right) / 190$

$\sigma^{2}=\frac{0.340 \times 190}{1.43 \times 0.342}$

$\sigma=11.49 \mathrm{~N} / \mathrm{mm}^{2}$

$F w=50 \times 20 \times 1.33 \times 0.340$

Since $\mathrm{k} \geq 0.34$

$F W=665 N>F d=452.68 \mathrm{~N}$

$F w>F d$

$\therefore$ The design is safe

Chain Drive

The specifications of sprocket wheels are as follows:

- Material= Mild Steel (tempered) and Stainless Steel

- Addendum diameter $=30 \mathrm{~mm}$ and $50 \mathrm{~mm}$

- No. of teeth=27 and 45

- Pitch $=12.7 \mathrm{~mm}$

Freewheel Specifications

- Material= Mild Steel (hardened)

- Addendum diameter $=50 \mathrm{~mm}$

- No. of teeth $=18$

- Freewheeling= one direction

- Pitch=14.6mm

$\Rightarrow$ The Chain Drive is used between the freewheeling sprocket and the largest of the rest of the two sprockets.

- Pitch $=10.5 \mathrm{~mm}$

- Roller diameter $=5.95 \mathrm{~mm}$

- Width $=5.85 \mathrm{~mm}$

- Breaking Load $=13,800 \mathrm{~N}$

[min. ISO Steel for Chain numbered 08A (ANSI-40)]

$>$ Design of Chain Drive

[MAT lab user interference]

- Material = Mild Steel [Hardened $]$

- Pitch $(\mathrm{P})=14.5$

- Speed $(n 1)=100 \mathrm{rpm}$

- No. of teeth $(Z 1)=18$

$$
\begin{aligned}
& U=\frac{\left(Z_{1} \times P \times n_{1}\right)}{60 \times 10^{3}} \\
& =0.435 \mathrm{~m} / \mathrm{sec}
\end{aligned}
$$

- Breaking Load $(w b)=15,800$

[ISO standard for chain number 08A (ANSI-40)]

- Power Rating $(\mathrm{KW})=0.1137 \mathrm{KW}$

Tension in Chain

$$
\mathrm{P}=\frac{(K W x 1000)}{r}=85.057 N
$$

Factors of Safety $\left(f_{s}\right)=\frac{W b}{P}=162.241$

Factor of safety obtained from the given design parameter is 162 . Hence the design is considered to be safe for static and fluctuating load

Bearing Calculations

Let us take (assume) single deep groove ball bearing Radial load $=F r=400 \mathrm{~N}$

Axial load $=F a \quad=500 \mathrm{~N}$

At speed $\mathrm{n}=160 \mathrm{rpm}$ and average life of 1 year at 4 hrs. per day Data: $F r=400 \mathrm{~N}$

$F a=500 \mathrm{~N}$

$\mathrm{N}=160 \mathrm{rpm}$

$L h=1$ year, $4 \mathrm{hr} /$ day

$=1 \times 365 \times 4=1460$ hours Assume shaft diameter 10 $\mathrm{mm}$

Let $\mathrm{d}=10 \mathrm{~mm}$, deep groove ball bearing series 0210 BC 02 / SKF 6200 Bearing is selected

For $\mathrm{d}=10 \mathrm{~mm}, \mathrm{D}=30 \mathrm{~mm}, \mathrm{~B}=9$

$\mathrm{r}=0.6 \mathrm{~mm}$

Static capacity: $C s=2360 \mathrm{~N}(2.00 \mathrm{KW})$ Dynamic capacity: $\mathrm{C}=5070 \mathrm{~N}(6.00 \mathrm{KW})$

Step 1: Equivalent load

$$
\mathrm{P}=(\mathrm{X} F r, \mathrm{Y} F a) \mathrm{S} \quad \mathrm{X}, \mathrm{Y}=\text { load factor }
$$

$F r, F a=$ radial $/$ axial $\mathrm{S}=$ Service factor

$$
\begin{aligned}
& F r=400 \mathrm{~N} \\
& F a=500 \mathrm{~N}
\end{aligned}
$$

$\mathrm{S}=1.6[\mathrm{M} / \mathrm{c}$ with sudden impact $]$ For $\mathrm{X}$ and $\mathrm{Y}$, in deep groove ball bearing

$$
\begin{gathered}
\frac{F_{A}}{C_{o}}=\frac{500}{2500}=0.211 \\
\frac{F_{A}}{C_{o}}=\frac{500}{400}=1.25>\text { e }(0.22 \text { to } 0.44) \\
\mathrm{X}=0.36 ; \mathrm{Y}=2 \\
\therefore \mathrm{P}=[0.56(400)+2(500)] 1.6 \\
\mathrm{P}=1958.4 \mathrm{~N}
\end{gathered}
$$

Step 2: Checking bearing capacity For N = 160 RPM

$\mathrm{L}=1460$ hours

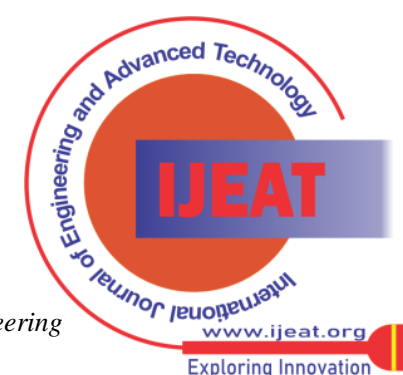


$$
\text { Loading ratio }=\frac{c}{p}
$$$$
\mathrm{C}=2.47 \times 1958.4=4857.248<[\mathrm{c}] 5070 \mathrm{~N}
$$$$
\therefore \text { Selected bearing is safe for design. }
$$

\section{IV.WORKING}

Vehicle shock absorberpower generation is very effective and needful in converting the Kinetic Energy from the movement of the vehicle, especially the suspension, which is not used, to generate electric energy that can be used to operate or workaccessories in the any vehicle. Now a days the batteries can be charged by attachments of IC engine shaft. So that the rotation of the shaft can be used to rotate thealternates to charge the battery, this usage is found to be $4 \%$ efficient of total consumption. In this newly designed model the generation of electricity is by attachment that can be placed in the suspension area to actuate. The advantage of this concept is energy storage can be possible in the system is possible using "BESS system" and driedbattery can be charged by ultra-capacitor using high frequency charge controller system. By installing this in all the available wheels, we can multiply the power of generation to themaximumextent this generatedelectric power can be utilized forair conditioner or refrigeration system of vehicles.

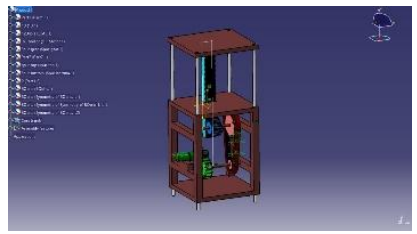

Fig 5.4(a) Isometric view of the 3D model

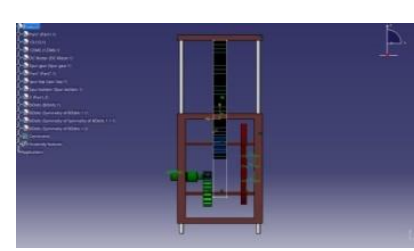

Fig 5.4(b) Front view of the 3D model

\section{CONCLUSIONS}

This suspension system will come in help for big and heavy compressed vehicles like, milk, fire brigade, refrigeration, where more electric power is required inside the vehicle Result; we are observed that for a little amount of vibration, we get the maximum power generation.

\section{ACKNOWLEDGMENT}

The authors express their thanks to HOD and staff of Mechanical Engineering Department, to the Principal of DBIT and to the Management of Wayanamac Education Trust, Bangalore, for the support and encouragement during this design and working of Suspension System.

\section{REFERENCES}

1. C.M. Pramodh, S.R. Shankapal 2013, "Regenerative shock absorber for hybridcars"

2. M. Sailaja, M. Raja Roy, S. Phani, "Design of rack and pinion mechanism for power generation at speedbreakers"

3. Zhongjie Li, Lei Zuo*, Jian Kuang, and George Luhrs "Energy harvesting shock absorber"

4. Rahul Uttamrao Patil, Dr. S.S. Gawade, "Design and static magnetic analysis of electromagnetic regenerative Shockabsorber"

5. Zhang Jin-qiu, Peng Zhi-zhao*, Zhang Lei, Zhang Yu, "A review on energy- regenerative suspension systems forvehicles"

6. Pei Sheng Zhang (2010) "Design of Electromagnetic Shock Absorbers for Energy Harvesting from VehicleSuspensions"

7. Pedro Portela, JoãoSepúlveda, JoãoSenaEsteves (2008) “Alternating current and Direct currentGenerator"
8. International Journal of Pure and Applied Research in Engineering and Technology, Research Article Impact Factor: 0.621 ISSN: 2319507X Swapnil Kamthe, IJPRET,2014; Volume 2 (9): 169-178IJPRET

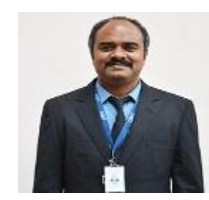

\section{AUTHORS PROFILE}

Somashekar R working as Assistant Professor in the Department of Mechanical Engineering, Don Bosco Institute of Technology with 10 years of Teaching and 4 years of Industrial Experience. The author has published two journal papers, three papers in international conference and one papers in national conference, life member of ISTE Email:somashekarr@hotmail.com

Sahana JStudent of Don Bosco Institute of Technology, Dept. of Mechanical Engineering Don Bosco Institute of Technology Bangalore-74, India Email: jagadeeshsahana1 @gmail.com

Akshay CStudent of Don Bosco Institute of Technology, Dept. of Mechanical Engineering Don Bosco Institute of Technology Bangalore-74, India Email: akshaymath130@gmail.com

Santhosh H CStudent of Don Bosco Institute of Technology, Dept. of Mechanical Engineering Don Bosco Institute of Technology Bangalore-74, India Email: santhu26982@gmail.com

SarveshStudent of Don Bosco Institute of Technology,Dept. of Mechanical Engineering Don Bosco Institute of Technology Bangalore-74, India Email: Sarveshm8788@gmail.com

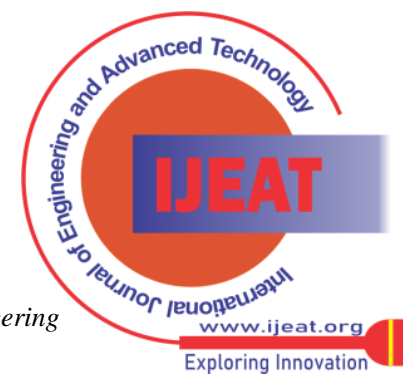

